\title{
O processo ou corpo de memória
}

\section{António Quadros Ferreira}

Portugal. Artista, professor catedrático da Faculdade de Belas Artes do Porto

antonio.quadros.ferreira@gmail.com 


\section{0. nota prévia}

Aparentemente ambiciosa e arriscada no assunto a abordar, esta comunicação, com o título de $\boldsymbol{O}$ processo ou corpo de memória, pretende suscitar alguma reflexão, nova e continuada, sobre um âmbito mais geral da pintura. De uma pintura considerada sem fronteiras, logo, sem territórios específicos ou exclusivos, tendo em conta um conceito mais amplo da pintura onde se assume uma dimensão mais expandida ou distendida nos seus propósitos circunstanciais e conjecturais.

Tendo como ponto de partida o universo, recíproco, da criação e da investigação em pintura, é nosso desejo sugerir a possibilidade do entendimento de que a pintura é um processo intelectual e um conhecimento em estado de recepção. Consequentemente, a ideia de que a pintura cumpre-se no intervalo entre o pensar e o fazer.

O mesmo que processo ou corpo de caminho?

Permanece, portanto, a pergunta sobre a possibilidade da lição da pintura. Lição na sua acepção mais ampla e que permite, no registo da recepção da criação artística, constatar as acções de revelar, de conhecer e de interpretar a transposição do conhecimento para a acção. Como estado de relação de um pensar e de um fazer em processo. Este será provavelmente o lugar, por excelência, da lição da pintura: a lição do que se deseja saber mas que não se sabe.

Por isso, esta comunicação não é mais do que uma exposição, aberta, uma espécie de texto pintado, ou pintura escrita, estruturada em cinco momentos: o primeiro, que pergunta a lição da pintura, o segundo, que relaciona a investigação entre a teoria e a prática, o terceiro, que diz o processo ou corpo de memória, o quarto, que aborda a structure molle como ideia operativa, e finalmente, o quinto e último momento, que pergunta se a pintura faz a lição em mundo. 


\section{1. a lição da pintura?}

É possível dizer a pintura? É possível investigar o dizer da pintura? Como dizer o que não se pode dizer? Como contar o que não se pode contar? O que é a pintura? O que é a pintura antes e depois da pintura? Como começa a pintura? Que revela a pintura?

Enquanto processo intelectual e conhecimento em estado de recepção, a pintura parece ser reveladora de uma instância simultaneamente de investigação e de criação. Consequentemente, a investigação em pintura, que mais não é do que criação (em pintura) é, com efeito, a investigação de um território, amplo, de compromisso e de meio, de um território que se cumpre no intervalo entre o pensar e o fazer. Neste contexto, a dimensão expandida que comporta a investigação em pintura é, em boa verdade, a da investigação intermédia ${ }^{1}$.

Investigação que diz um modo operatório de (se) percorrer um caminho, de facto e de método. Um caminho que revela e mostra um processo que opera os modos possíveis de se realizarem relações repertoriais. Por isso, se a pintura é o como se faz (depois, ou antes, do como se pensa), eventualmente preservada de um excesso de teoria, na opinião de Yves-Alain Bois, pois tudo se obscurece se procuramos pelo sentido de tudo, então, sem serem jogadas na experiência sensorial, que é a pintura, todas estas palavras são nada, e ou podem não ter significado algum, principalmente quando "il y a plus de vérité dans ce qui se cache que dans ce qui se voit", como nos refere Gaston Bachelard.

A arte, em geral, e a pintura, em particular, parece ser feita de vios e de desvios. Com efeito, o intervalo (da obra de arte) é provavelmente o lugar do caminho que (ainda) não existe, ou que não se vê. O intervalo é o que pode explicar a inexplicação da pintura (?). O intervalo parece ser, então, o verdadeiro lugar do processo, ou do caminho que concilia o pensar com o fazer. Exaltando o destino e a dúvida do homem, a pintura acontece. E acontece como fim ou consequência do processo².

O processo é já uma primeira instalação: uma instalação mental - de pensamento e de construção. Por isso, o pensamento constrói-se, e a sua construção não é passível de ser violada ou interrompida. Trata-se de um tempo prévio onde tudo acontece incondicionalmente. 
A transposição do pensamento para a acção pode, pelo contrário, significar a perversão do próprio pensamento ou ideia. A única maneira de o corrigir estará na estratégia de se reassociar à aç̧ão um pensamento novo que reinstaure a ideia primeira, ou que instaure uma nova ideia (em qualquer situação sempre diferente).

Relação de um pensar e de um fazer em processo, relação de um processo que se faz em caminho.

O processo organiza e prepara o pintor para a pintura.

Para a pintura enquanto pergunta de muitas perguntas.

O que revela uma pintura? Não se pode criar uma forma original sem se abrir a formas do passado. Quando Harold Bloom diz que Shakespeare lê de um modo mais completo do que pode ser lido, leva-nos a interrogar se um pintor não vê de um modo mais completo do que poder ser visto. Os artistas que inovam estão profundamente ligados à tradição e praticam a lição da pintura pela pintura. As variações ou recriações artísticas são um diálogo íntimo com a obra, são o desvendar de um enigma e uma história da arte feita pelos pintores.

A teoria que a prática contém é a que decorre de um acto de investigação, enquanto que a prática que a teoria potencia é a que se abre de um acto de criar. Por isso, a intersecção do âmbito da criação com o âmbito da investigação, enquanto âmbitos, convergentes, de um estado de relação, de contexto, ou de arte. A pintura é, assim, definitivamente, um estado de arte: porque faz e pensa, porque pensa e faz.

É importante que haja uma nítida percepção do que é ou do que poderá ser a investigação em pintura e dos seus precisos modelos de investigação, dos contextos dos temas e da viabilização da discussão dos mesmos em grupos, no pressuposto de que a investigação em pintura pode ser também do âmbito das migrações disciplinares, da relação entre investigação e ensino, e ainda da relação entre o pensamento e a comunicação (a investigação mediada pela comunicação, ou a investigação suscitada como exercício de um pensar que liga, inevitavelmente, a teoria à prática) ${ }^{3}$.

Tanto a pintura como a investigação, que lhe é inerente, pensa-se como estado de conhecimento, que o mesmo é dizer, como estado tanto de produção como de recepção. Ou, as sugeridas simultaneidades entre o estado de conhecimento do que é a investigação na pintura, e do que é a pintura na investigação, convocam-se como 
instâncias funcionalmente múltiplas do que pode ser o entendimento da investigação em pintura, nomeadamente, a) a investigação como reflexão, b) a investigação como processo intelectual, e c) a investigação como acto comunicativo.

\section{2. a investigação entre a teoria e a prática}

A interrogação faz nascer um projecto de caminho, faz percorrer um caminho de viagem. E, como todos os caminhos e viagens, a imprevisibilidade do estar condiciona a natureza do ser. O caminho, onde a violência da pureza e da simplicidade são inquestionáveis, é o caminho do pensar e do fazer, é o caminho do fazer falar a pintura, o caminho do processo ou corpo de memória, isto é, o caminho do autor e da obra.

Entre a teoria e a prática, o objecto artístico e pictórico parece ser o de um lugarterritório, onde se concita o pensar e o fazer, o revelar e o mostrar, e o reflectir e o produzir, como sendo algumas das circunstâncias do universo artístico. Lugar-território que, ocupando um antes e um depois, é o da pertença de um presente, de um durante. Por isso, lugar-território ou espaço-tempo que suscita consignar a fenomenologia do objecto artístico numa relação tríade, onde a latência é determinante para se compreender a extensão de um fio que une a origem (antes) ao resultado (depois). Isto é, a latência que se situa entre o que não se sabe ao que se julga saber. Que se situa entre momentos como os de reunir ou desejar com os de compor ou de condicionar, ou o que nos propõem autores tão distantes e tão próximos, entre si, como Alberti e Valéry.

Em antecipação ao fazer, ou ao pensar, o autor transporta dentro de si todo o universo referencial de todos os seus objectos, de toda a sua obra, de toda a sua vida. A obra enquanto dimensão autoral compreender-se-á como um estado (de acto e) de fé. O caminho será assim o lugar onde a interrogação se sustenta em narrativas de investigação, que o é muito mais pelo processo que se adopta enquanto memória de um percurso, do que pelo propósito de apropriação de um modelo alicerçado tanto em conceitos teóricos avulsos como em questões enquadráveis em estados da arte ou de revisão da literatura. 
O processo de criação, do domínio da acção e do visível, do objecto e do corpo que em imagem se dá a ver, é o modo que permite observar o artista e a obra em estado de relação, e a obra e o fruidor em estado de instalação (a instalação da obra é um projecto de resultado, é um exercício onde se dispensa, ou se congela, o tempo, é um corpo de imagem que se insinua para além do olhar). A montante é o desconhecido e o desconhecimento total e absoluto. É do âmbito do que não se sabe, ou âmbito de um intervalo. Mas é aqui onde tudo começa, embora não se sabendo. Onde se originam as condições, decisivas, para a criação.

O processo de criação instala-se a partir de um estado de permanente relação que se desenvolve entre um pensar e um fazer. Instala-se em pensamento de coerente determinação de um caminho que se diz, e que diz. O processo de criação é a possibilidade de se organizar, ou de se compor, ou de se instalar, ou de se relacionar, um caminho. Uma ideia de caminho que é, já, em deriva de um corpo de imagem. Para deixar de o ser, depois?

$\mathrm{Na}$ investigação em pintura o seu objecto não deve ser circunstancial ou conjuntural, antes corresponder a um trabalho que encontrará o seu foco essencial na obra artística. Será uma espécie de investigação total, porque absolutamente autobiográfica? Com a prática (e a teoria) da investigação é possível atingir propósitos muito ambiciosos em torno dos processos de criação artística. Processos que se constróiem naturalmente, sem um normal modelo de acção, mas que nos faz revelar sempre o caminho como caminho de uma ideia.

Nesta conformidade impõe-se compreender a ideia enquanto modo ou acontecimento da arte. Dir-se-ia que a arte acontece, nomeadamente, como ideia que alimenta o pensamento e a realização, seja do domínio teórico seja do domínio prático, como nos diz René Pradel: "I'art n'apparaît pas comme un objet mais comme une idée, il réside plus dans une volonté que dans la réalité et l'essence de l'art se confond avec l'acte de créaction $(. . .)^{4}$. Pelo que é a ideia que permite germinar o caminho da criação artística, o caminho que, sendo da criação, é obviamente do processo que fundamenta as acções de dizer e de fazer: "Sans cesse le créateur doit pouvoir lier consciemment sa volonté de dire à sa volonté de faire, à son désir de médiatiser sa pensée $(\ldots)^{5}$.

Espécie de magma ou continente de um caminho com duas direcções, a ideia 
medeia sempre o sentido entre a produção e a recepção, em relação comprometida entre o que se diz e o que se faz. Sublinhe-se que a recepção, sendo também da competência dos artistas, quando no passado o foi dos historiadores e ou dos críticos, é do seu âmbito porque justamente existe uma recepção reflexiva e passível de consubstanciar, de novo, uma acção de retorno ao pensar o fazer, e ao fazer o pensar, uma acção de retorno a um princípio de investigação-criação. Por isso, falamos da recepção entendida enquanto visão artística, ou uma espécie de mediação entre o que foi já objecto de criação e a criação que pode vir a ser materializada em objecto novo.

(Mas) o tema ou assunto, qualquer que ele seja, é sempre o território comum e privilegiado de uma deriva, igual à do pensamento (que sem aparente norte inventa), e que permite alimentar sem fim todos os gestos e fluídos criativos. Por isso, a investigação que em estado relacional entre a teoria e a prática se constata, porque aberto às singularidades que o tempo suscita enquanto totalidade que contém os espaços todos (intersticiais) e imaginários de um movimento imprevisível ou impensável que é aquele que acontece no domínio da relação entre a reflexão e a produção, entre a teoria e a prática, entre o processo e o acontecimento, entre a obra e a obra depois da obra. Uma espécie de eterno retorno - entre a obra e o autor.

Verdadeiramente uma investigação teórico-prática parece diluir-se, ou confundirse, com o que se designa de criação artística. Investigação teórico-prática ou investigação implícita que decorre no interior do pensamento teórico, enquanto lugar de sistema e de ordem, que adequa a inteligência à sensibilidade, que nos diz que a arte é, afinal, e sempre, um processo que constrói um caminho único de verdade. De verdade da obra: onde tanto a arte e a ciência, como a pintura e a estética, coabitam e se fundem; onde a investigação implica-se na criação, e a teoria na prática; onde tanto a arte é um processo intelectual, um conhecimento em estado de recepção, como nos diz Almada Negreiros, como o essencial da pintura é o essencial do mundo, como nos diz Daniel Arasse; ou o que persegue a arte e a pintura é, finalmente, uma espécie de sentido de eterno. A teoria estética parece assim organizar-se, finalmente, numa dimensão absolutamente relacional entre o arbitrário e o não arbitrário (entre o caos, aparente, e a ordem, certa), entre o singular que inicia e o plural que continua. 
Entre o pensar e o fazer institui-se uma relação, coerente, de previsibilidade interna. Uma relação que reflecte a liberdade de decidir que em instâncias diferentes se cumpre. O pensamento molle é, por isso, crucial para que o discurso seja simultaneamente circular e possível, isto é, um discurso que não seja exclusivo, apenas, do pensar ou do fazer. Mas exclusivo de um pensar para fazer, e de um fazer com pensar. Aliás, como nos sugere Arnaud Villani:

La pensée molle c'est le fini-infini, le peirar apeiron des bagues sans limites, c'est le renversement circulaire des discours "tressés" (...) C'est le départ dans un espace non inscrptible, avec des traces que nul ne peut suivre (...) Un lieu mou est un "lieu sans lieu", origine de tous les lieux. (...) Un temps mou réintroduirait dans la valorisation du temps de travail, du temps objectif et cosmique, l'imprévisible du rythme vivant, de la faveur du momento (Kairos) de la liberté (scholé, otium). (...) Una communication molle implique le silence, le secret, le négatif. Dans cette communication négative (Kierkegaard), ce qui se transmet n'est rien et cela ne peut se faire que par le vide crée par le séducteur. La contagion sans transport de matière est "double réflexion. (... $)^{6}$.

A pintura enquanto exercício de um pensamento estético activo acontece porque se pensa no momento em que se decide, ou parece decidir-se. E quando se decide deixa de ser pensada? É aparentemente possível concluirmos que é viável pensar-se a pintura, fazendo-a. Na realidade, é sempre possível realizar a pintura, pensando-a. A única diferença reside na circunstância de que o pensar (parece que) antecede o fazer, num primeiro momento do fazer. A pintura é formulada, então, de um modo total, sem subterfúgios, sem calculismos, sem redes. A pintura está constituída porque o fazer a pintura não perturba a coisa pensada (e a pensar?) como metáfora da descoberta do Novo. 

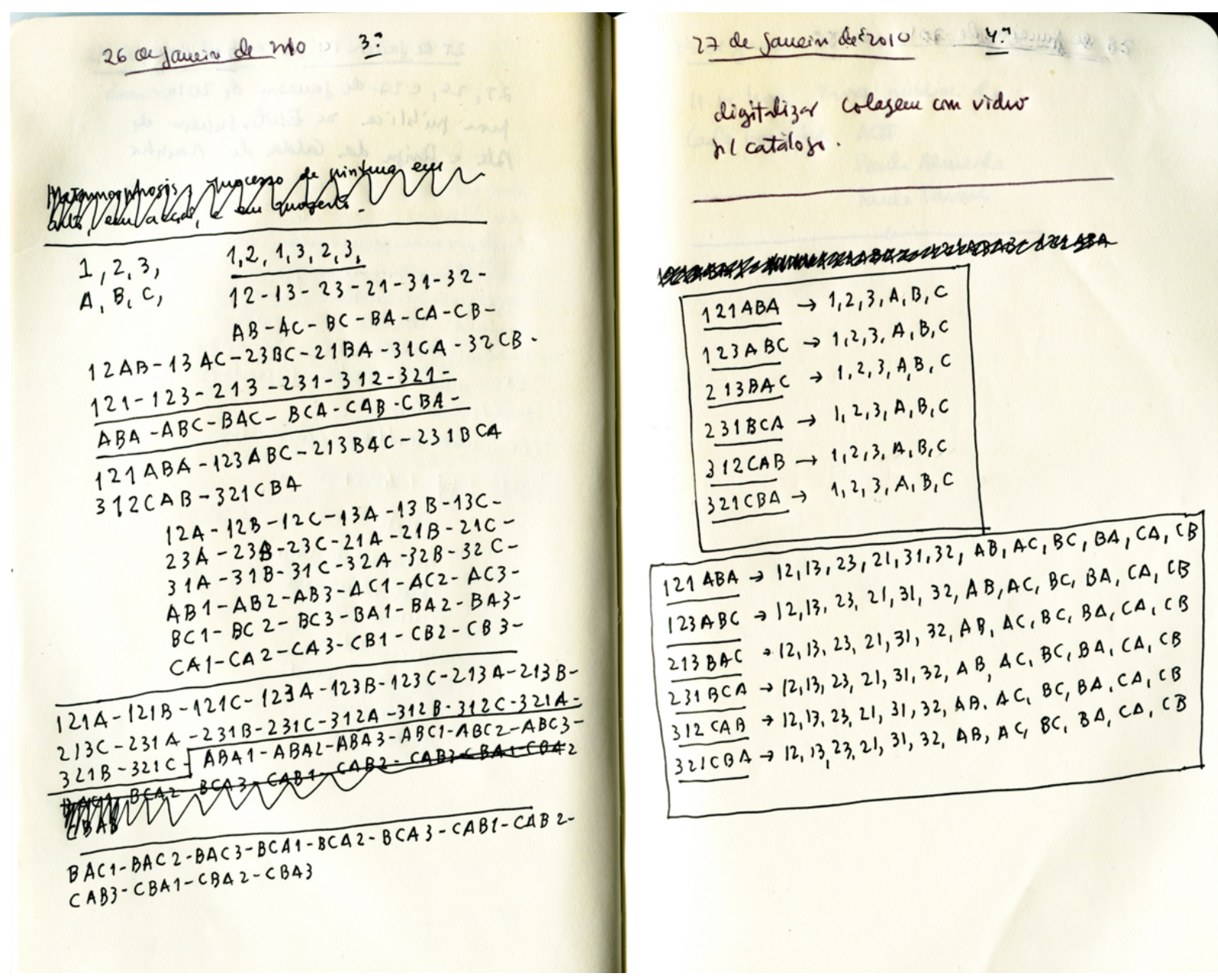

Figura 1 - António Quadros Ferreira, Estudo para METAMORPHOSIS, 2010, caneta sobre papel, $20,9 \times 29,7 \mathrm{~cm}$.

\section{3. o processo ou corpo de memória}

Os processos, que são do âmbito da criação e da recepção, do âmbito também das opções estéticas e de composição, como ainda do âmbito do sentido do (in)útil e do (dis)funcional, mais não fazem do que classificar e sistematizar, em modo de se dar a ver (e de se dar a fazer?) o sentido do conhecimento que, em arte e em pintura, é do domínio da invenção.

A condição do processo é verdadeiramente a condição da viagem, de uma viagem: 
pensar o processo é já fazer a viagem enquanto procura criativa de uma identidade e de um sentido. A viagem é por isso uma espécie de prática que inventa uma metodologia de caminho. É essa metodologia (o como, e o modo) que permite inspirar e realizar a viagem. Viagem enquanto entidade e conceito puro ou aplicado, objectivo ou subjectivo, que possibilita entendimentos múltiplos acerca do espaço e do tempo. A viagem primeira impõe-se como inexplicável condição original para a invenção proporcionada pelo movimento, extensão, deslocamento, e percurso, de lugares e tempos, de um processo ou corpo de memória.

A viagem antes da viagem (ou processo antes do processo) é já o lugar de uma espécie de ruptura nómada, ou a ideia de viagem como enunciação da não viagem, por exemplo, que nos permite pensar a imagem como mãe de todo o pensamento. Mãe e condição de um pensamento que acciona o processo como lugar da intenção e da extensão. A viagem que se pensa e que se faz é verdadeiramente a viagem de um caminho único e singular - caminho que orienta aquilo a que designamos de método ou de metodologia e que mais não faz do que caracterizar a especificidade do que é irrepetível - o exercício da arte e da pintura. É já em caminho de projecto que se revela o processo de uma certa itinerância dos objectos (picturais), nas suas progressões e regressões, nas suas sístoles e diástoles, nas suas rupturas e (des)continuidades. Por isso, a pintura, tal como o pensamento, não existe sem aquilo que o força a realizar, tanto em estado de criação como em estado de investigação.

Em projecto o programa ou reportório deseja organizar as relações de um processo, entre o pensamento e a prática, deseja integrar num todo a totalidade da acção e da reflexão artísticas. O processo artístico parece ser o que realiza, no essencial, a procura de um sentido. Um sentido de criação artística. Mas o sentido corresponderá sempre a uma lógica de construção, de narrativa e de retórica, articuladas, reciprocamente. Um processo que parece ser central e transversal tanto à criação como à investigação.

O processo da pintura é, de facto, o que concretiza a fusão dos limites e das diferenças, entre a linha e a forma, entre a superfície e a cor, entre o gesto e a acção, entre o discurso e a narrativa, na presunção de que o movimento da pintura é, prioritariamente, a do acto de pintar. A pintura, onde o gesto total permite supor, e 
sustentar, o princípio de que, no fundamental, o exercício artístico consuma-se numa aparente (?) relação dialéctica entre o facto e o lugar. Facto do desenho, e lugar da pintura? Ou desenho do lugar, e pintura do facto?

Entre o lugar e o facto a fronteira ou limite. Por isso, as fronteiras dissipadas tornam difusas as diferenças operatórias. Com efeito, é obviamente evidente que existe uma preocupação em conciliar factos e lugares, independentemente da estratégia em si. Se mais ou menos pintura, se menos ou mais desenho, ou se mais e menos invenção, relativamente a um assumido sistema operatório. E, dessa maneira se culmina uma correspondência inquestionável entre gesto e memória. Em ausência de um sistema de regras a imprevisibilidade, o inesperado, ou a surpresa, consubstanciam o que Dubuffet defendeu como exercício paradigmático de uma estética inconformada, ou estética sem referências ("le vrai art, il est toujours là où on ne l'attend pas").

A pintura de um gesto total, ou de um gesto incondicionado, projecta um olhar novo sobre o nosso quotidiano em atenção suscitada por um princípio de paysage $d u$ mental, na designação de Michel Ragon. O impulso, do gesto (e da acção), projecta-se no acto de pintar. Toda a pintura é a de um gesto circulatório de um movimento circulatório: gesto da incondição de uma arquitectura do lugar (ou desenho da pintura), em quotidiano sempre veemente. Pintura aparentemente totalitária, contudo, de um gesto da paixão pela matéria presente ou ausente, pelo rigor da memória, e pela exaustão de um gesto de liberdade absoluta: pintura da acção do gesto total, pintura de muitos gestos, pintura de muitas pinturas, onde o gesto é claramente o de uma dimensão verdadeiramente teatral (e ou cinematográfica), em registo de uma narrativa, de uma história, e de um testemunho.

O processo pode, no limite, tudo explicar, não explicando. Isto é, o processo é uma espécie de totalidade de um corpo de caminho onde não se sabe quando se começa e quando se acaba o acto mesmo de construção e de dizer de um objecto, de realização de uma narrativa, de enunciação de uma investigação. A ideia de que o princípio da explicação é possível só o é de facto verificável quando o acto de explicar implica a possibilidade mesma de um conhecimento. Mas existe a certeza de que a impossibilidade de obtenção de conhecimento acontece como imperativo do inexplicável, a par ou em estado de coabitação com a explicação que mais não é do que 
uma resultante objectiva de conhecimento em estado de acontecimento.

O processo contém o explicável e o inexplicável, regista o que pode ser conhecido e o que não é conhecido. De facto, “(...) Ce qui peut être connu, c'est la permanence des effets $(. . .)^{\prime 7}$. O que quer dizer o seguinte: o que é do âmbito do desconhecido é sempre o contrário da permanência do efeito, isto é, do que não se sabe, de uma espécie de realidade difusa, híbrida, e indescritiva, como que comandada por um princípio simultâneo de acaso e de indeterminismo. Por isso, o processo, enquanto corpo de caminho (e de memória), inclui a totalidade da investigação que se deseja em estado de acção artística, e ou em estado de reflexão crítica. De uma outra maneira, enquanto contexto de um acontecimento e acontecimento de um contexto.

Em boa verdade o processo, como totalidade de um caminho, tem sempre um começo e um fim. Mas, paradoxalmente, o que se sabe será sempre do que permanece no meio (no presente) - lugar privilegiado da realidade do acontecimento. O que estará antes (começo) e o que estará depois (fim, ou recomeço), aparentemente pertença de dois contextos não coincidentes porque distintos, serão de facto inexplicáveis, ou de explicação infundamentada. O que se pode eventualmente explicar é o que se situa sempre num território de centro, ou de meio, ou de intervalo, ou de corpo - de um caminho que em estado de consciência e convicção se transforma em enunciado de obra, ou em obra de enunciado, isto é, em objecto ou acontecimento. A permanência dos efeitos está no corpo de um caminho de processo em estado de momentânea paragem.

Sendo que um processo parece ser central e transversal tanto à criação como à investigação, entendido como estratégia de fundamento e de fusão, o que está por detrás do princípio das structures molles $^{8}$ é inegavelmente a questão do processo e do método. Isto é, o que fundamenta e justifica a acção de pensar e de fazer e, neste contexto, a decisão mesma enquanto opção. Decidir é escolher, é seguramente realizar opções. É sempre o espaço de um caminho que se deseja percorrer. Um caminho de processo. De processo enquanto lugar único da diferença. O que significa dizer que estaremos perante a necessidade da diferença como procura do que é essencial para um exercício de mudança e de transformação. A acção da arte é esta mesma: a do processo que constrói o caminho, e a do caminho que constitui o processo, sendo o grande critério 
constituído por uma emergência de diferenciação. Como bem nos refere Arnaud Villani em ligação com a essência da estrutura das coisas:

\begin{abstract}
La différentiation est la constellation du virtuel, la différentiation en est l'actualisation (...) l'histoire est un corps indéterminé, un grand flux, un sujet larvaire, c'est-à-dire un être sans identité, sans linéarité et déplacé par rapport à toute totalisation, à côté de l'universel dont il se sert en fait, par une ruse de la raison inversée. (...) Structure molle, c'est-à-dire, à venir, mais indéterminée en profondeur, toujours déplacée par rapport aux prévisions, (...) le mou, le potentiel, l'indéterminé, la physis suscitent en général, comme si entre chaos et cosmos, il ne pouvait y avoir, du moins pour une pensée du "comput", ce point d'hésitation du chaosmos, qui, comme métamorphique, permet toutes les rencontres $(\ldots)^{9}$.
\end{abstract}

A procura da diferença é sempre a procura de um novo, de um fluxo larvar que diz e que actualiza, que resolve o caos e o cosmos e, nesse contexto, cumpre um pensamento que é o de uma ordem que se determina no indeterminado.

Para Michel Sanouillet as structures molles adaptam-se e adequam-se a toda a criação artística, a todo o processo artístico: a structure molle (que se situa entre l'absence de sens e le sens, segundo Arnaud Villani), corresponderá a uma abordagem que revela e que cria, que elabora na ambiguidade das decisões a possibilidade da modernidade. Tornando o caminho da arte e da pintura um caminho de enorme imprevisibilidade. Pelo que, e de facto, "le chemin des peintres est droit et courbe", segundo Héraclite. Em suma, mais do que uma filosofia de acção e de comportamento, ou um instrumento de análise e de construção, ou até um estado de espírito, as structures molles são, ou parecem ser, na opinião de Tony Tschaegle, um conceito, onde:

La construction sémantique du concept repose sur une dialectique qui est le reflet de notre monde (...) les structures molles sont l'expression les structures molles sont l'expression de la liberté. Les structures molles ne sont pas le reflet de la stabilité, mais celui de l'adaptation continue, dans un monde en pleine mutation ${ }^{10}$. 
Aliás, na transposição das structures molles para o processo, Tony Tschaegle acrescenta ainda o seguinte:

Les "structures molles" se veulent évolutives, mais chaque "moment" fait partie intégrante du tout avec les acquis des "moments précédents". La pensée se veut globale. Nous prenons le mot "pensée" au sens d'Engels: "la dialectique dite objective opère dans la nature, et la dialectique subjective, dite "pensée", ne fait que refléter le mouvement entre les conbtraires et leur passage final en un autre qui, par le conflit continuel des oppositions et leur passage final en un autre ou en une forme plus élevée, détermine la vie de la nature"11.

\section{4. a structure molle como ideia operativa}

Pensar arte, ou fazer arte, é pensar o vestígio, ou fazer a utopia, e permitem a organização de um tempo de memória, de densidade e de projecto. Como em Jackson Pollock, ou em Nan Goldin, onde parece ocorrer uma similar natureza de gestão da ideia do processo e do projecto que concentra, principalmente no artista e na obra, o sentido do que é, ou do que pode ser, o entendimento da arte contemporânea. O artista faz parte, então, da “(...) densidade de um continuum não censurado, que nem começa nem termina com qualquer decisão ou acção da sua parte", na opinião de Robert Rauschenberg ${ }^{12}$. O que poderá significar, talvez, que, se a arte começa com o artista, não termina com a obra. Cada vez mais a obra, que se socorre de múltiplos processos, linguagens, estratégias, e expressões, será a possibilidade de uma lógica de simultaneidades, de junções, de associações. De uma estética do absoluto passar-se-ia a uma estética da relação (que em Pollock e em Goldin não se suscita em óbvia separação de modelos), ou a uma estética da surpresa, como estética formulada por um pensar, mais do que formulada por um agir, enquanto sentido essencial de uma típica formulação discursiva, formal e instalatória, que se implementou decisivamente na segunda metade do século $\mathrm{XX}^{13}$.

Na reciprocidade entre a liberdade e a relação reside, também, a aporia da arte: a da impossibilidade do absoluto. De um qualquer absoluto. Ou, ainda, a ideia de que o 
contexto, que se sobrepõe à obra é, de facto, o de um elemento radicalmente novo que condiciona as formas e as estéticas. Desta maneira, embora em suportes diferentes, assumem-se igualmente as contribuições, não só de Pollock ou de Goldin, como ainda de toda a segunda metade do século $X X$, no sentido de um acréscimo que pode significar o rumo ou a certeza de um colapso eminente, e de lucidez de um equilíbrio instável. Justamente por via de um contexto, novo e radical, que nos remete para uma melhor compreensão da própria natureza da obra e do seu objecto.

A teoria estética, qualquer que ela seja, organiza-se sempre em torno de um sistema e de uma estrutura. Segundo leis geométricas essenciais, a estrutura que se preconiza fará coabitar a razão das regras com a emoção das intuições. Pelo que a teoria estética só poderá ser de natureza aberta e flexível. Por isso, não podemos falar de estruturas rígidas, mas antes falarmos de structures molles (de acordo com o conceito definido e defendido por Michel Sanouillet) ${ }^{14}$.

A teoria estética mais não é do que a previsível reflexão e a solução do conflito ou tensão entre a ordem e a desordem. Pretende a teoria estética sistematizar um processo de criação, do mesmo modo que as structures molles privilegiam também o sensível? 0 acto criador poderá acontecer, sempre, entre o mou e o aleatório? O termo mou (que imana das structures molles) parece definir-se entre a matéria e a forma, onde Arnaud Villani nos sugere que "toute structure est molle: (e que) le mou est la terra inconnue, le réel à l'oeuvre, le point d'hésitation comme pontage incessant de la matière et de la forme" 15 .

As structures molles implicam, por isso, e de certo modo, uma determinada especificidade difusa, a da arte, na sua relação mesma com a investigação:

En effet, les structures molles demandent une pédagogie molle, dont la définition et les techniques restent encore très difficiles à appréhender (...) Nous nous sommes donc résignés à un compromis entre le désir légitime de savoir, exprimé par nos interlocuteurs potentiels, et notre souci non moins légitimement fondé de préserver le sens d'une démarche originale. (...) plus que les champs épistémologiques des diverses disciplines concernées, ce qui importe par-dessus tout, c'est le processus communicationnel lui-même, le cheminement qui condicionne, 
dans sa nature, sa forme et ses fonctions, le transfert $d^{\prime}$ information et donc l'ensemble des relations sociales ${ }^{16}$.

A própria noção de structures molles parece derivar de uma praxis e de um modus operandi, associando-se à teoria molle o respectivo postulado:

Théorie molle, c'est-à-dire un ensemble de données constamment fluctuantes, évanescentes et difficilement préhensibles, dont le mouvement $n$ 'est pas régi par des lois permanentes et scientifiquement démontrées par l'expérience, mais selon des algoritmes appartenant en l'état actuel de nos connaissances au domaine de l'aléatoire ou du stochastique (...) le domaine propre des structures molles, qui ne se peut réduire ni à une discipline déterminée, ni à un thème particulier, ni à une doctrine, ni à un phénomène localisé dans le temps ou dans l'espace (...) Nous savons bien que le mouvement vrai, le vivant, c'est lui justement qui ne se décompose pas et le secret des structures molles se dissimule peut-être dans cet intervalle subliminalement perceptible qui sépare deux images pelliculaires. $(\ldots)^{17}$.

Oriundo que foi nos anos imediatos aos de Maio de 68 , quando se discutia a realidade política e a forma de a alterar, assim como a ruptura com as designadas estruturas rígidas tanto sociais como culturais, face aos enormes avanços tecnológicos, muitos dos intelectuais da Escola de Nice, liderados pelo Professor Michel Sanouillet, e inspirados por Marcel Duchamp, permitiam adoptar a dúvida no centro da decisão (e acção) artística como uma espécie de fórmula metafórica "en distendant un peu les réalités physiques et chimiques" na opinião de Jacques Monod citado por Michel Sanouillet ${ }^{18}$.

Numa perspectiva bem mais vasta, e até radical, dir-se-ia que o conceito de estrutura aplicável a uma grande diversidade de situações, mas com prevalência para as situações da fenomenologia artística, corresponderia a um conceito novo, ou até ecológico. Porque toute structure est molle, como bem definiria Arnaud Vilani, a propósito do termo mou do seguinte modo explicitado:

Le terme "mou" en effet, bien plus nettement que "souple", "fluide", "multiforme", semble plus intuitif et connoté que rigoureux (...) le mou est la qualification essentielle, eidétique et transcendentale, de la structure en tant que singularité (...) La matière serait, selon la mythographie usuelle, le "réceptacle" que la forme viendrait remplir ou mouler ${ }^{19}$. 
Existem diferentes formas de investigação em arte? Isto é, diferentes metodologias de investigação artística? Uma investigação que se pode situar entre a aplicação e a abstracção? E o processo que conduz à criação da obra de arte? É, de facto, do âmbito da criação ou da investigação? A contemporaneidade impõe-nos o ambíguo como condição da fusão dos territórios e das fronteiras, dos espaços e dos limites, das contingências e das liberdades. Por isso, as similitudes devem ser entendidas como momentos que advêm da necessidade de reflectir e de criar: de reflectir sobre a criação, e de criar sobre a reflexão ${ }^{20}$.

A consciência da investigação que se procura para além daquela que existe implícita à própria pintura será sempre a da possibilidade de afirmação de paradigmas epistemológicos absolutamente novos. Por outro lado, e porque é de metodologias de acção que se trata, não é possível a imposição exterior de modelos de investigação artística em arte estranhos à própria arte, porquanto o princípio do modelo estrangeiro ou exterior é, aparentemente, contraditório com o princípio da criação. Pelo que, em vez da ideia de modelo, é mais aceitável a ideia de estratégia operativa que intervém reiteradamente para se dar resposta a assuntos e ou a perguntas. O princípio da criação é o da liberdade, isto é, o do livre arbítrio, pelo que, a ideia de modelo investigativo enquanto regra de um sistema operativo e funcional parece ser sempre impossível em arte. 


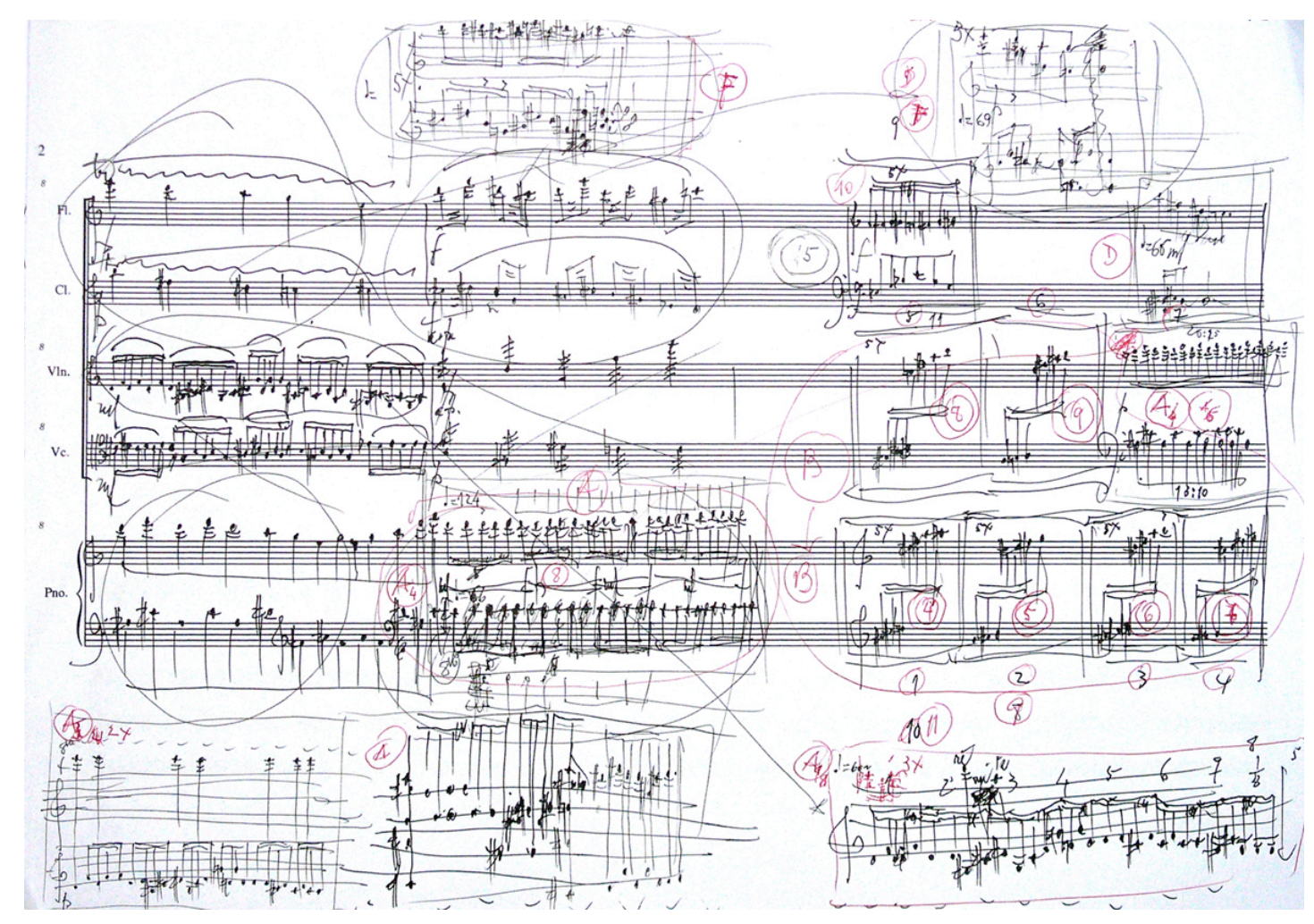

Figura 2 - Cândido Lima, Estudo para OPTIC MUSIC, QUADROS CINÉTICOS, 2010, caneta sobre papel, 20,9×29,7cm.

\section{5. a pintura faz a lição em mundo}

O exercício da pintura procede, ou é o resultado do cumprimento de regras de acção que consubstanciam uma resposta adequada e conciliada com os superiores interesses da pintura enquanto processo dinâmico de investigação. Isto é, a assumida investigação em pintura, que se confunde com o normal desempenho artístico e estético da pintura, e na pintura, é a da investigação que se realiza no respeito por um processo.

O processo da pintura é o do acto de pintar.

E o acto de pintar é o que corrobora comportamentos outros que se prendem com a eficácia e o efeito para a produção da pintura e dos seus objectos possíveis.

Normalmente, a pintura é o resultado de uma transferência de matéria (e ou de uso), de enunciado em estado de discurso, pelo que, a transferência mediada pelo autorartista, é a que decorre de um movimento de mediação. $O$ artista é o mediador, mas é 
também o autor. Mediador porque concretiza o projecto autoral, autor porque antecipa a função da mediação. Nesta circunstância o papel único do artista, insubstituível.

Por outro lado, e decorrente de uma estratégia de pensar o acto de pintar, e o modelo de organização e de gestão da pintura, a questão prática da transferência de material da pintura para a pintura, isto é, de material de pintura para o suporte da pintura, que o mesmo é dizer, da paleta para a tela. $\mathrm{O}$ transfert ou a transferência de um lugar para o outro, de um lugar primeiro, plural, e desorganizado (com ou sem caos), para um lugar último, singular, e organizado. A qualidade da pintura não reside somente na diferença entre a paleta e a tela, reside também no menor ou maior grau de interferência que é possível introduzir no caminho que concretiza o acto de pintar. A pintura é a consequência, então, de uma diferença, e de uma perturbação. Mas é, também, a consequência de um fascínio e de uma exaltação.

Nesse espaço de meio, de lugar, ocorre a investigação, a criação, o objecto.

Assim, falamos de formas ou de lados (no interior) da investigação artística. Formas ou lados da investigação (lado de cá e lado de lá) onde a comunicação é ou poderá ser uma instância mediadora e crucial entre o objecto da arte (que dispensa a comunicação) e o objecto da investigação (que necessita da comunicação). Não obstante, existe a função comunicativa. Função que junta ou aproxima, ou que separa ou distancia, as duas instâncias nucleares: a da criação e a da investigação. A metalinguagem da comunicação sugere-nos que a fronteira entre o lado de dentro e o lado de fora é absolutamente imperceptível. Fronteira que tanto separa como aproxima, e onde a comunicação parece influenciar decisivamente o trânsito entre o estado de criar e o estado de investigar.

De facto, investigar em pintura não é obrigatoriamente traduzir, por palavras, o que é ou o que pode ser a imagem pictórica. A palavra, podendo descrever a investigação enquanto constructo comunicacional, é manifestamente insuficiente e eventualmente imprópria: a investigação não se esgota, por isso, na palavra que diz a reflexão, ou na palavra que eventualmente prepara ou recepciona a produção. A investigação percorre outras metalinguagens, incluindo as que são portadoras do universo da criação artística. Por isso, a investigação artística só poderá acontecer, e sobreviver, no interior do processo da criação, isto é, em estado de absoluta relação com 
o acto de fazer. A investigação artística supõe-se como instância de um pensar que se funde para um fazer.

Toda a obra é uma obra de acto e de autor. Toda a arte é a da procura de uma permanência (e persistência) do absoluto fundada no princípio do novo. Princípio de um projecto que nos permite pensar o artista-pintor enquanto corpo falante de um discurso. Toda a procura da vertigem do absoluto pode ser inscrita na liberdade do acto de pintar, pelo que não é possível separar o autor da obra, ou a obra do autor, sob pena de tal pressuposto conduzir-nos ao paradigma da arte sem artistas, ou de artistas sem arte. Todo o gesto aspira ser de um absoluto: de um instante do absoluto o gesto que, repetindo-se na sua acção de persistência, repete-se também na sua adequação processual.

Na pintura, de silêncios e de conflitos, de rastos e de realidades, o suporte é supostamente o lugar de uma narrativa de todos os lugares. Desse modo, o gesto localiza-se entre o excesso e a ausência, libertando-se em acontecimento de um fazer. Estratégia de uma imprevisibilidade total: pintura, por isso, de um permanente efémero ou em trânsito, que se discorre entre o desenho e a pintura. Toda a obra plástica corresponde a um exercício de síntese configurando um princípio de oscilação entre uma ideia de forma e um gesto de matéria, pelo que, e em situação de liberdade absoluta, tanto a autobiografia como a memória possibilitam configurar uma ideia de processo de extrema e radical importância seminal.

A pintura parece ser o lugar e o objecto de um discurso de vida que não se distancia do enunciado que Ihe precede. Tudo acontece por um impulso, total e, desse modo, o gesto não é o do discurso, ou só do discurso - que concretiza um enunciado, é antes a de um movimento, permanente e (im)preparado. Pintura que arrisca, pintura que preenche e que ocupa, em expressão pessoal a pintura que questiona a aprendizagem e a desaprendizagem.

O livre arbítrio da arte é o que verdadeiramente caracteriza o processo do acto de pintar: o acto de criar como acto de decidir; pintura de fazer com as mãos, pintura de desafio das regras, dos limites, das tradições, e das histórias. Antes de ser pintura o gesto é o da acção, do desenho enquanto movimento, que faz prevalecer a arte como 
linguagem de uma periferia e de um centro; no processo o fascínio do momento do dizer; na pintura a verdade de um fazer em ambiente de gestão de acasos e de acidentes.

O julgado aparente arbítrio da pintura, que nos envolve, e que nos provoca, isenta ou não o desempenho de um papel central da pintura enquanto estratégia, projecto, e processo? Enquanto expressão, linguagem, disciplina, e método, para a afirmação lúcida da criação artística?

Investigar e ou criar remete-nos, sempre, para uma consciência dos territórios artísticos que se situam entre o pensar e o fazer, e se movem entre processos e projectos. Em conciliação de narrativas e de discursos (de objectos verdadeiramente singulares) a consciência da investigação permitiria acrescentar ciência a factos e a acontecimentos que, desse modo, tornar-se-ia numa espécie de acrescento ou extensão de uma inquietação onde a experimentação se opõe desejavelmente a uma dimensão de congelamento ou fixação. Muitas das vezes o que a investigação faz é traduzir fixando, limitando, comunicando. Mas a investigação que interessa é a que se insta e que se funde como mecânica de uma natureza artística essencial.

A investigação artística, a que dá a conhecer o acto de criar, é a da reflexão do que se produz, mas também a da produção do que se reflecte. Investigar em arte é ensaiar a compreensão tanto da correspondência entre o estado de teoria e o estado de prática, como da correspondência entre o como se faz e o como se pensa. A investigação artística é, consequentemente, o como se organiza, mas também é o como se dá a conhecer: fazendo-se pensar e pensando-se fazer ${ }^{21}$.

Pelo fazer a criação melhor se pensa como criação.

Pelo pensar a criação melhor se faz como reflexão e ou como produção da obra, em sede, seja da criação, seja da recepção.

A prática artística é o centro da investigação?

Investigação para pensar e fazer tanto a teoria como a prática artísticas?

Antes e depois da pintura o que é a pintura?

Para concluir, e como nos diz Michel Sanouillet, o modo operatório é a grande emergência do processo enquanto corpo de memória, para a pintura pensar e fazer $a$ lição em mundo: "Plutôt que de définir le produit mou ou celui qui n'est plus mou, moi, ce qui m'intéresse, c'est le mode opératoire"22 


\section{6. notas}

1. Por investigação intermédia julgar-se-á uma investigação fundamental, de meio, ou de centro, situada entre a reflexão e a produção, entre o pensar e o fazer, e que, por isso, fará a ponte entre uma investigação teórica e uma investigação teórico-prática. A investigação diz um modo operatório que percorre um caminho, de facto e de método. Um caminho que revela e mostra um processo que opera os modos possíveis de se realizarem relações repertoriais.

2. O intervalo é uma continuidade, ou um momento (oportunidade) de desvio? Ou um tempo de continuidade diferencial? Ou o intervalo, apenas, de um lugar de preparação para a mudança (a mudança faz-se sempre a partir de desvios)? O intervalo parece ser o espaço, aparentemente sem tempo nem espaço, onde se organizam as condições do autor, primeiro, e da obra, depois. O intervalo é já o princípio da obra, antes do pensar, mas é também já o fim da obra, depois do fazer. O intervalo não é objectivamente o tempo nem do pensar nem do fazer. O intervalo, sendo aberto e fechado, flui como ponte de um rio que descreve um caminho de margens. O intervalo é decisivo, porque é aí que tudo se prepara e se faz: decisivo porque se mapeia o invisível das coisas. Este invisível é o verdadeiro mistério. Contudo, entre o mistério do que ainda não se vê, ou do que ainda não existe, e o mistério do que já se vê e que existe, acontece o intervalo enquanto diferença entre a ausência e a presença. A investigação total em pintura é, decisivamente, aquela que se faz no lugar e caminho do atelier.

3. A observação, ou a experiência do artista-pintor, que apenas pratica o seu ofício, ou a experiência do docente-investigador, que partilha o seu conhecimento, por exemplo, são algumas das realidades bem diversas que podem enriquecer a diversidade da investigação, no sentido de se assegurar ou garantir um sólido corpo de pensamento reflexivo. Muitas questões ou caminhos da investigação em pintura podem ser identificados face ao trabalho em rede ou em equipa. Tornar-se-á imprescindível a criação de um chão que permita a consolidação de algumas derivas no sentido de se organizar a construção de uma narrativa viável neste domínio. E, pela narrativa, ou não, a pintura acontece como fim ou consequência do processo. De um processo enquanto corpo de memória.

4. PREDAL, René. "Bernard-I'Ermite super star: audio, visuel et mou". In Médianalyses, Cahiers de recherches communicationnelles, numéro 3/4, dedicado ao tema "Structures Molles", Centre du XXe Siècle, Nice, janvier 1984, p. 41.

5. FERRIER, Eric, GUILLEMONT, Benoît. "Le non indifférent médiat entre créateur et message", In Médianalyses, Cahiers de recherches communicationnelles, numéro 3/4, dedicado ao tema "Structures Molles", Centre du XXe Siècle, Nice, janvier 1984, p. 48.

6. VILANI, Arnaud. "Contribution à l'étude des structures molles: métamorphose, pensée des fluides, ordre et désordre". In Médianalyses, Cahiers de recherches communicationnelles, numéro 3/4, dedicado ao tema "Structures Molles", Centre du XXe Siècle, Nice, janvier 1984, p10. 
7. MARTA, Monique. "Regards sur la fleur d'amandier". In Médianalyses, Cahiers de recherches communicationnelles, numéro 3/4, dedicado ao tema "Structures Molles", Centre du XXe Siècle, Nice, janvier 1984, pp. 142-143.

8. A designação de structures molles corresponde a um termo-conceito definido por Michel Sanouillet, e que pretendia propor o entendimento de que seria possível um desdobramento ou leitura outra à ideia de estrutura: em alternativa ao princípio da estrutura rígida, a possibilidade da existência de estruturas dissipativas, alternativas, ou abertas.

9. VILANI, Arnaud. "Contribution à l'étude des structures molles: métamorphose, pensée des fluides, ordre et désordre". In Médianalyses, Cahiers de recherches communicationnelles, numéro 3/4, dedicado ao tema "Structures Molles", Centre du XXe Siècle, Nice, janvier 1984, p4.

10. TSCHAEGLE, Tony. "Les strucures molles comme dynamique de l'application des théories économiques dans un espace rigide". In Médianalyses, Cahiers de recherches communicationnelles, numéro 3/4, dedicado ao tema "Structures Molles", Centre du XXe Siècle, Nice, janvier 1984, p. 119.

11. Idem. Ibidem.

12. Citado por Oyvind Fahlström, in Art and Literature 3, 1964, p. 219.

13. Entre Jackson Pollock e Nan Goldin o igual e o diferente surgem, embora com estratégias diferentes, como paradigmas cruciais de um modo de se pensar, e de se fazer, a arte contemporânea. Se toda a pintura é desejo de memória, a obra é, então, anseio de uma expressão seminal, expectativa de uma realidade nova (sem pintura, sem escultura?). Autores como Donald Judd, Frank Stella, ou Steven Parrino, convocam-nos para uma ideia de objecto em ruptura eminente com o princípio da superfície ou do plano. Nesta conjuntura, tanto a pintura invadiu o espaço do espectador, como o espectador se vê confrontado com estratégias novas de recepção.

14. O Centre du XXe Siècle, da Université de Sophia Antipolis (Nice) publica, em Janeiro de 1984, o número $3 / 4$ da revista Médianalyses, Cahiers de recherches communicationnelles, um conjunto de textos, seminais, dedicados ao tema das "structures molles". Este tema de investigação foi muito dinamizado pelo Professor Michel Sanouillet, da referida universidade francesa, e presidente da Associação Internacional para o Estudo de Dada e do Surrealismo, fazendo com que do seu entusiasmo tivessem ocorrido outras formas de pensar nomeadamente a recepção artística, ligando-se a recepção à dimensão e contexto autorais. As "structures molles" pretendiam então enunciar, enquanto princípio e filosofia, uma reflexão profunda sobre os mecanismos da criação artística, configurando-se a ideia de que a questão crucial é a do caminho que condiciona, isto é, do modo operatório. De um modo muito inequívoco, 
e a propósito do âmbito mesmo do que pode ser a structure, o mou ou a mollitude, diznos Michel Sanouillet o seguinte: "La question que je me pose est la suivante: est cequ'une structure molle existe vraiment ou bien n'est-elle qu'un concept de l'esprit?".

15. VILANI, Arnaud. "Contribution à l'étude des structures molles: métamorphose, pensée des fluides, ordre et désordre", in Médianalyses, Cahiers de recherches communicationnelles, numéro 3/4, dedicado ao tema "Structures Molles", Centre du XXe Siècle, Nice, janvier 1984, pp. 1-10.

16. SANOUILLET, Michel. Introduction, in Médianalyses, Cahiers de recherches communicationnelles, numéro 3/4, dedicado ao tema "Structures Molles", Centre du XXe Siècle, Nice, janvier 1984, pp. III-XII.

17. Idem. Ibidem.

18. Idem. Ibidem.

19. VILANI, Arnaud. "Contribution à l'étude des structures molles: métamorphose, pensée des fluides, ordre et désordre". In Médianalyses, Cahiers de recherches communicationnelles, numéro 3/4, dedicado ao tema "Structures Molles", Centre du XXe Siècle, Nice, janvier 1984, pp. 1-10.

20. Por outro lado, pensar o fazer pode muito bem ser o fio que une os dois lados da investigação em arte e em pintura. Lados esses que, relacionáveis, possibilitam ou impossibilitam fazer falar a pintura. Tendo em conta a complexidade deste assunto não é possível a existência, objectiva, de respostas absolutas ou certas, porquanto o que está em causa é do domínio da arte, ou com ele comprometido. Pelo que, não existe uma resposta por antecipação ou prévia pois, a investigação do que se cria é, ela própria, portadora de incerteza.

21. Lugar de lugares, ou lugar de interrogações, a investigação em pintura pode e deve decorrer da circunstância de se ensaiar o seu pensar e o seu fazer em estado de relação e em estado de contexto com o acto de criação artística. Deste modo qual o grande desígnio da investigação em pintura? Fazer a pintura? Falar a pintura?

22. SANOUILLET, Michel. In Médianalyses, Cahiers de recherches communicationnelles, numéro 3/4, dedicado ao tema "Structures Molles", Centre du XXe Siècle, Nice, janvier 1984, p.153.

Porto, 19 de Novembro de 2015 